\title{
Nutrition knowledge and other determinants of food intake and lifestyle habits in children and young adolescents living in a rural area of Sicily, South Italy
}

\author{
Giuseppe Grosso ${ }^{1, *}$, Antonio Mistretta ${ }^{1}$, Giovanna Turconi ${ }^{2}$, Hellas Cena $^{2}$, \\ Carla Roggi ${ }^{2}$ and Fabio Galvano ${ }^{3}$ \\ 'Department 'G.F. Ingrassia', Section of Hygiene and Public Health, University of Catania, Via Santa Sofia 87, \\ 1-95123 Catania, Italy: ${ }^{2}$ Department of Applied Health Sciences, Section of Human Nutrition and Dietetics, \\ Faculty of Medicine, University of Pavia, Pavia, Italy: ${ }^{3}$ Department of Drug Sciences, Section of Biochemistry, \\ University of Catania, Catania, Italy
}

Submitted 5 February 2012: Final revision received 21 May 2012: Accepted 17 June 2012: First published online 29 August 2012

\begin{abstract}
Objective: The study aimed to test the reliability of a nutrition questionnaire and to assess potential associations between nutrition knowledge, food consumption and lifestyle behaviours, controlling for sociodemographic factors.

Design: Cross-sectional survey.

Setting: Comprehensive school in the municipality of Butera, a rural area of Sicily, South Italy.

Subjects: The survey was conducted between March and May 2010 on 445 students (4-16 years).

Results: All constructs of the questionnaire had statistically significant Cronbach's $\alpha$ and Pearson's correlation coefficients, showing good internal consistency and temporal stability. After controlling for covariates, nutrition knowledge was positively associated with pasta/rice, fish, vegetable and fruit intakes, and negatively with sweets, snacks, fried foods and sugary drinks consumption. Moreover, students whose parents were in the highest educational and occupational categories reported eating significantly more fruits and vegetables and less meat, sweets, snacks, fried foods and sugary drinks. Students with higher nutrition knowledge scores were less likely to have two or more snacks daily and to spend more than $3 \mathrm{~h}$ in sedentary activities daily (OR $=0 \cdot 89,95 \% \mathrm{CI} 0 \cdot 83,0 \cdot 97$ and $\mathrm{OR}=0 \cdot 92,95 \% \mathrm{CI} 0 \cdot 86,0 \cdot 99$, respectively). High parental education was associated with less frequent snacking and more frequent weekly physical activity, compared with lower categories, whereas high parental occupational category was associated with daily breakfast.

Conclusions: Improving nutrition knowledge in children and young adolescents may translate into educating them in good dietary habits. Moreover, nutrition intervention programmes should also involve parents to improve dietary quality and nutritional habits of the entire family.
\end{abstract}

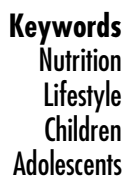

Over the past decades, a growing body of scientific literature has focused on finding the association between nutrition knowledge and food consumption, leading to inconclusive results ${ }^{(1)}$. Indeed, the strength of such associations has been found to vary among the studies and is generally weak. Reasons for failure are not well understood. Although the suggestion that knowledge is one of the determinants of food choice may seem intuitive, several psychological and environmental factors might play a role in such choice, leading to a different attitude towards changing behaviour for health reasons. Thus, the findings of a study might depend on the study population.
Childhood and adolescence is a period when a diet of good nutritional quality is important to establish healthy behaviours concerning food consumption that influence adult morbidity and mortality ${ }^{(2)}$. Despite the familial environment being well known to influence the food intake of children, childhood is a crucial period of life, since children begin to learn food concepts and a lack of knowledge concerning nutrition and health can cause the onset of poor behavioural traits that have a tendency to carry over from childhood to adulthood. On the other hand, adolescents might also be strongly influenced by friends and mass media, and they may attend school 
programmes on nutrition. Thus, despite it not being well established if there is a relevant association between nutrition knowledge and dietary habits in adults, several studies have addressed the positive impact of knowledge on nutritional behaviour in children and adolescents ${ }^{(3-5)}$.

The present study used a newly elaborated tool to measure nutrition knowledge, food frequency and eating behaviours, specifically developed for children and young adolescents (aged 4-16 years), to assess whether nutrition knowledge corresponds to some dietary behaviour and nutritional lifestyle habits. The study aimed to test the reliability of the questionnaire and to assess potential associations between nutrition knowledge, food consumption and lifestyle behaviours (i.e. breakfast and snacking habits, physical and sedentary activity), controlling for sociodemographic factors (such as gender, age, BMI, parents' educational and occupational categories).

\section{Materials and methods}

\section{Participants}

The survey was conducted between March and May 2010 among students attending a comprehensive school located in the municipality of Butera, a rural area of Sicily, South Italy. Given the school made up the whole population of students aged 4-14 years and older students aged 15-16 years still in secondary school (about 500 children), our sample is highly representative of a typical rural area of Sicily. Participation was voluntary and informed consent was obtained from students' parents. The study was approved by the ethics committee of the University of Catania. The administration of the questionnaire was performed in classroom during school time in the presence of a trained doctor and a referent teacher, after a short lecture and illustration of the same. It took about 20 min to complete the questionnaire.

\section{Developing the questionnaire items pool}

The choice of the questions to be included in the questionnaire was made after a review of the literature concerning nutrition knowledge, eating behaviours and lifestyle advice. Questions were collected by an accurate selection of items in already existing questionnaires or obtained on the basis of research in order to represent the entire topic to be measured. Thus, a pool of ninety-two items generated by a group of experts, composed of three doctors and two nutritionists, was obtained. In accordance with previous studies ${ }^{(6)}$, the panel of experts was asked to indicate whether or not a measurement item was 'essential' to the operationalization of a theoretical construct. The content validity ratio was calculated by the formula:

$$
\operatorname{CVR}=\left(n_{\mathrm{e}}-n / 2\right) /(n / 2),
$$

where CVR $=$ content validity ratio, $n_{\mathrm{e}}=$ number of experts indicating 'essential' and $n=$ total number of experts.
This formula yields values which range from +1 to -1 ; positive values indicate that at least half of the experts rate the item as essential. The mean CVR across items may be used as an indicator of overall test content validity.

This process reduced the number of items to fifty-four divided into six broad sections as described below.

1. Food consumption frequency. This section consisted of twelve questions aimed at assessing the frequency of consumption of foods and beverages, paying specific attention to the major food groups. Respondents were asked how many times they consume the foods, scoring the frequency in ten option categories ('seldom/never', ' 1 per month', '2-3 per month', '1 per week', '2-3 per week', '4-6 per week', ' 1 per day', '2-3 per day', ‘ $4-5$ per day' and ' 6 or more per day').

2. Meal habits. This section consisted of seven items designed to investigate children's qualitative preferences and food choices at meals.

3. Breakfast and snaking habits. The entire section, consisting of four items, examined frequency characteristics associated with breakfast and snacking habits.

4. Influences on food choice. This section aimed at assessing if parental control and television viewing (especially during meals) may influence children's and adolescents' nutritional habits or consumption of not normally advertised food. It contained nine items addressing factors influencing respondents' eating habits and food consumption.

5. Lifestyles and physical activity. This section consisted of six questions with three or four response categories assessing the frequency of physical activity, television viewing or computer use, smoking habits, and attitude to spending leisure time in activities involving movement or rest.

6. Nutrition knowledge. This last section contained twenty-two questions focusing on a few topics meant to influence respondents' food choices and eating habits: food nutrients, food contents, healthy foods and drinks, and energy expenditure. Questions provided four possible options with a single correct answer and an additional answer, 'Not sure,' to discourage missing data.

Questions on personal data were finally added to collect information about students' class, age, gender, weight and height. BMI evaluation, based on self-reports of weight and height, was used to assess overweight and obesity rates according to Cole et al.'s classification ${ }^{(7)}$. In order to investigate familial socio-cultural status, parents' educational and occupational status was investigated and the highest category among the mother and father was taken into account for the analysis. Younger children were helped by a trained doctor to fill in this section of the questionnaire.

The reliability of the questionnaire was tested on a pilot sample of ninety-three students recruited from the same 
school. The sample was based on a cluster design with the school class as a basic unit of sampling to ensure recruiting a similar number of students per age group. Participants were encouraged to report any confusion with the questionnaire and were assured of complete anonymity. The teacher and the doctor were asked to note and report any difficulties and questions raised during the questionnaire compilation.

The test-retest reliability has been measured by administering the questionnaire on two different occasions. We assumed that a time interval of 2 weeks between the two administrations was long enough to avoid recall bias and short enough to avoid changes in the studied attributes.

The questionnaire developed in this work is available in the Supplementary Materials.

\section{Statistical analyses}

Baseline characteristics are presented as absolute and relative frequencies of occurrence or mean and standard deviation as appropriate. Differences between groups were tested by the $\chi^{2}$ test for categorical variables, while for continuous variables parametric (Student's $t$ ) and nonparametric (Mann-Whitney $U$ ) tests were computed after controlling for homogeneity of variance (Levene test).

Internal consistency was measured by computing Cronbach's $\alpha$ coefficient ${ }^{(8)}$. The closer $\alpha$ is to one, the higher is the reliability estimate of the instrument. According to classical test theory principles, the minimum requirement for internal consistency is recommended as $0 \cdot 60^{(9)}$. In addition, we computed Pearson's correlation coefficient as a measure of temporal stability. Cronbach's $\alpha$ and Person's correlation coefficients were computed for the total score of each section with the exception of the sections assessing food consumption frequency and meal habits, because these sections are not scaled (rather similar to an FFQ) and there is no total score. Therefore, we evaluated the temporal stability of each item of both these sections. Moreover, we additionally divided the section concerning nutrition knowledge in four constructs (food nutrients, food contents, healthy foods and drinks, and energy expenditure) and computed Cronbach's $\alpha$ for each of them.

To graphically plot food consumption according to nutrition knowledge level, weekly food consumption was calculated and a scale was developed according to relative quartiles of nutrition knowledge scores to facilitate ranking. To test if a significant difference occurred between mean weekly consumption of foods according to nutrition knowledge ranks, Student's $t$ test and the Mann-Whitney $U$ test were again computed as appropriate.

Multiple linear regression modelling was used to study the relationship between weekly food consumption and nutrition knowledge scores (both considered as continuous variables) and to assess if nutrition knowledge was an independent predictor of food consumption adjusting for covariates such gender, age, BMI and parental educational and occupational categories. Multivariate regression models were performed to test if nutrition knowledge was an independent predictor for specific lifestyle habits, adjusting for the same covariates. Lifestyle behaviours investigated in the survey were breakfast, snacking, physical and sedentary activity habits. $P \leq 0.05$ was considered significant for all statistical tests conducted. All analyses were performed using the SPSS statistical software package release $17 \cdot 0$.

\section{Results}

\section{Sample characteristics}

A total of 472 participants were recruited for the survey. Missing questionnaires were almost exclusively due to absent students. Of the 472 questionnaires collected, twenty-seven had missing, incomplete or inconsistent answers, resulting in a total of 445 questionnaires eligible for the analysis.

Demographics are presented in Table 1 . The mean age of participants was 8.73 (SD 2.94) years (range 4-16 years). Gender was approximately equal in representation, with boys accounting for slightly more of the participants $(51 \cdot 8 \%)$. There were no substantial differences between girls and boys although the former were significantly more likely to be overweight or obese $(P<0 \cdot 001)$.

\section{Questionnaire reliability}

Cronbach's $\alpha$ values indicated acceptable internal consistency for each of the four sections of the questionnaire taken into account (Table 2). All constructs had values above $0 \cdot 7$; the only exception was the section regarding lifestyles, with Cronbach's $\alpha$ equal to 0.676 indicating moderate internal consistency of this section. Internal consistency was also assessed for each construct of the section regarding nutrition knowledge, finding Cronbach's $\alpha$ values equal to 0.807 (food nutrients), 0.769 (food content), 0.639 (healthy foods and drinks) and 0.671 (energy expenditure; data not shown).

Pearson's correlation coefficients were calculated between test and retest for the four sections of the questionnaire and resulted in high reliability, with correlation coefficients ranging from a minimum of 0.699 (lifestyles section) to a maximum of 0.874 (nutrition knowledge; Table 2). All correlation coefficients were statistically significant with $P<0 \cdot 001$.

Pearson's correlation coefficients of each item assessing frequency of food consumption and meal habits are shown in Table 3. All Pearson's correlation coefficients were statistically significant with $P<0 \cdot 001$. In the section regarding food consumption, correlation coefficients ranged between 0.430 (question about water consumption) and 0.885 (question about pasta and rice consumption), resulting in good temporal stability with the exception of the item 
Table 1 Demographic characteristics of the study population: children and young adolescents $(n 445)$ aged $4-16$ years living in a rural area of Sicily, South Italy, 2010

\begin{tabular}{|c|c|c|c|c|c|c|c|}
\hline & \multicolumn{2}{|c|}{ Total $(n 445)$} & \multicolumn{2}{|c|}{ Males ( $n$ 230) } & \multicolumn{2}{|c|}{ Females ( $n 215)$} & \multirow[b]{2}{*}{$P$} \\
\hline & Mean or $n$ & SD or $\%$ & Mean or $n$ & SD or $\%$ & Mean or $n$ & SD or $\%$ & \\
\hline Age (years) & $8 \cdot 73$ & $2 \cdot 94$ & $8 \cdot 78$ & $2 \cdot 99$ & $8 \cdot 67$ & $2 \cdot 89$ & $0 \cdot 71$ \\
\hline Age group $(n, \%)$ & & & & & & & 0.765 \\
\hline$<6$ years & 82 & $18 \cdot 4$ & 45 & $19 \cdot 6$ & 37 & $17 \cdot 2$ & \\
\hline $6-10$ years & 174 & $39 \cdot 1$ & 87 & $37 \cdot 8$ & 87 & $40 \cdot \overline{5}$ & \\
\hline$>10$ years & 189 & $42 \cdot 5$ & 98 & $42 \cdot 6$ & 91 & $42 \cdot 3$ & \\
\hline $\mathrm{BMI}\left(\mathrm{kg} / \mathrm{m}^{2}\right)$ & $19 \cdot 69$ & $2 \cdot 34$ & $18 \cdot 85$ & $2 \cdot 26$ & $18 \cdot 52$ & $2 \cdot 40$ & $0 \cdot 138$ \\
\hline BMI classification* $(n, \%)$ & & & & & & & $<0.001$ \\
\hline Underweight and normal weight & 212 & $47 \cdot 6$ & 89 & $38 \cdot 7$ & 123 & $57 \cdot 2$ & \\
\hline Overweight & 183 & $41 \cdot 1$ & 113 & $49 \cdot 1$ & 70 & $32 \cdot \overline{6}$ & \\
\hline Obese & 50 & $11 \cdot 2$ & 28 & $12 \cdot 2$ & 22 & $10 \cdot 2$ & \\
\hline Parents' education ( $n, \%)$ & & & & & & & 0.514 \\
\hline None or primary & 2 & $0 \cdot 4$ & 0 & 0 & 2 & 0.9 & \\
\hline Secondary & 150 & $33 \cdot 7$ & 76 & $33 \cdot 0$ & 74 & $34 \cdot 4$ & \\
\hline High school & 179 & $40 \cdot 2$ & 94 & $40 \cdot 9$ & 85 & $39 \cdot 5$ & \\
\hline University & 114 & $25 \cdot 6$ & 60 & $26 \cdot 1$ & 54 & $25 \cdot 1$ & \\
\hline Parents' occupation ( $n, \%)$ & & & & & & & $0 \cdot 619$ \\
\hline Unskilled professions & 17 & $3 \cdot 8$ & 8 & 3.5 & 9 & $4 \cdot 2$ & \\
\hline Partially skilled professions & 83 & $18 \cdot 7$ & 39 & $17 \cdot 0$ & 44 & $20 \cdot 5$ & \\
\hline Skilled professions & 188 & $42 \cdot 3$ & 96 & $41 \cdot 7$ & 92 & $42 \cdot 8$ & \\
\hline Specialized/managerial & 157 & $35 \cdot 4$ & 87 & $37 \cdot 8$ & 70 & $32 \cdot 6$ & \\
\hline
\end{tabular}

${ }^{*}$ According to Cole et al.'s classification ${ }^{(7)}$.

Table 2 Internal and test-retest reliability of the sub-sample for questionnaire reliability $(n$ 93)

\begin{tabular}{lcc}
\hline Section & $\begin{array}{c}\text { Internal reliability } \\
\text { (Cronbach's } \alpha)\end{array}$ & $\begin{array}{c}\text { Test-retest reliability } \\
\text { (Pearson's correlation coefficient) }\end{array}$ \\
\hline Breakfast and snack habits & 0.774 & 0.769 \\
Influences on food consumption & 0.711 & 0.801 \\
Lifestyle & 0.676 & 0.699 \\
Nutrition knowledge & 0.780 & 0.874 \\
\hline
\end{tabular}

*All $P$ were $<0.001$.

concerning water consumption. In the section concerning meal habits, correlation coefficients ranged between $0 \cdot 701$ and $0 \cdot 850$, again showing good temporal stability.

\section{Nutrition knowledge levels}

Findings regarding the association between demographics and nutrition knowledge are reported in Table 4. Means and standard deviations of nutrition knowledge scores are shown to highlight demographic differences. Higher nutrition knowledge scores were significantly associated with being underweight or normal weight $(P=0 \cdot 003)$, older $(P<0 \cdot 001)$ and having parents in a higher educational $(P<0 \cdot 001)$ and occupational category $(P<0 \cdot 001)$.

Regarding the percentage of correct answers according to different constructs, among the group of questions concerning food nutrients the best basic knowledge was found on the item regarding the definition of vitamins (56.9\% correct answers) and the worst on the item about balanced diet (37.5\% correct answers). Knowledge about food contents was found to be generally acceptable, with about half of the students responding correctly to all items with the exception of the one regarding pasta and bread content $(42.7 \%$ correct answers). The construct concerning healthy foods and drinks had the highest variation of correct answers, ranging between $59 \cdot 3 \%$ for the question about difference between fruit and juice and $37 \cdot 1 \%$ for the one about yoghurt and yoghurt cake. Finally, the percentage of correct answers in the construct on energy expenditure did not vary among items, with almost half of the students responding correctly to all questions, although correct answers to the question regarding food intake according to energy expenditure reached $57 \cdot 8 \%$ (data not shown).

\section{Nutrition knowledge and food consumption}

Weekly food consumption according to quartile of nutrition knowledge score is plotted in Fig. 1. Being in the higher quartile of nutrition knowledge score was associated with significantly higher consumption of pasta/rice $(P=0 \cdot 001)$, vegetables $(P<0 \cdot 001)$ and fruit $(P<0 \cdot 001)$ and significantly lower consumption of sweets $(P<0 \cdot 001)$, snacks $(P<0 \cdot 001)$, fried foods $(P<0 \cdot 001)$ and sugary drinks $(P=0 \cdot 004)$. The effect was more clearly directly linear for vegetables and fruit and inversely for meat, sweets, snacks, fried foods and sugary drinks, rather than for the other food categories.

As diet varied significantly with nutrition knowledge, it was possible that the association between knowledge 
and some food consumption was caused by their both being correlated with demographic characteristics. After controlling for covariates such gender, age, BMI, parents' education and occupational categories, nutrition knowledge was independently positively associated with pasta/rice, fish, vegetables and fruit intakes, and negatively associated with sweets, snacks, fried foods and sugary drinks consumption (Table 5). The stronger associations were found between nutrition knowledge

Table 3 Test-retest reliability for the twelve-item section on food frequency consumption and seven-item section on meal habits ( $n$ 93)

\begin{tabular}{lc}
\hline Questionnaire item & $\begin{array}{c}\text { Test-retest reliability } \\
\text { (Pearson's correlation coefficient) }\end{array}$ \\
\hline Consumption frequency of & $0 \cdot 885$ \\
Pasta or rice & $0 \cdot 710$ \\
Meat or chicken & $0 \cdot 655$ \\
Fish & $0 \cdot 603$ \\
Cheese & $0 \cdot 656$ \\
Eggs & $0 \cdot 609$ \\
Vegetables & $0 \cdot 766$ \\
Fruits & $0 \cdot 752$ \\
Sweets & $0 \cdot 864$ \\
Snacks & $0 \cdot 684$ \\
Fried foods & $0 \cdot 873$ \\
Sugary drinks & $0 \cdot 430$ \\
Water & $0 \cdot 810$ \\
Meal habits & \\
Most frequent foods at & $0 \cdot 701$ \\
breakfast & $0 \cdot 843$ \\
Most frequent fast food & $0 \cdot 850$ \\
Most frequent snack & $0 \cdot 736$ \\
Where eat breakfast & $0 \cdot 767$ \\
With whom eat breakfast & $0 \cdot 781$ \\
With whom eat lunch & \\
With whom eat dinner &
\end{tabular}

and fish $(\beta=0 \cdot 630)$, vegetables $(\beta=0 \cdot 203)$, fruit $(\beta=0 \cdot 129)$ and sweets $(\beta=-0 \cdot 168)$ intake. Moreover, educational level and occupational level were independently associated with the consumption of several foods (Table 5). Those in the highest educational and occupational categories reported eating significantly more fruits $(\beta=0.253$ and $\beta=0.228$, respectively) and vegetables $(\beta=0 \cdot 226$ and $\beta=0 \cdot 328$, respectively); while those in the highest educational category reported less meat $(\beta=-0 \cdot 188)$, snacks $(\beta=-0 \cdot 304)$, fried foods $(\beta=-0 \cdot 422)$ and sugary drinks $(\beta=-0 \cdot 438)$. Among the other covariates analysed, BMI was found to consistently interact with sugary drinks consumption $(\beta=0 \cdot 158)$, and age with fruit $(\beta=0.066)$ and vegetables $(\beta=0.097)$ consumption.

\section{Nutrition knowledge, lifestyle and dietary bebaviours}

In order to see whether nutrition knowledge was an independent predictor of lifestyle and dietary behaviours such as breakfast and snacking as well as physical and sedentary activity frequencies, multiple regression modelling was used. Regression analysis revealed that nutrition knowledge was independently associated with snacking and sedentary activity. Students with higher nutrition knowledge scores were less likely to have two or more snacks daily and to spend more than $3 \mathrm{~h}$ in sedentary activities daily (OR $=0 \cdot 89$, $95 \%$ CI $0.83,0.97$ and $\mathrm{OR}=0.92,95 \%$ CI $0.86,0.99$, respectively; Table 6). Moreover, the multivariate model revealed that also age, gender, educational category and occupational category were independently associated to some nutritional and lifestyle behaviours (Table 6). In brief,

Table 4 Distribution of nutrition knowledge scores according to demographic characteristics of the study population: children and young adolescents $(n 445)$ aged $4-16$ years living in a rural area of Sicily, South Italy, 2010

\begin{tabular}{|c|c|c|c|}
\hline \multirow[b]{2}{*}{ Variable } & \multicolumn{2}{|c|}{ Nutrition knowledge score } & \multirow[b]{2}{*}{$P$} \\
\hline & Mean & SD & \\
\hline Gender & & & $0 \cdot 819$ \\
\hline Male & $9 \cdot 9$ & $2 \cdot 9$ & \\
\hline Female & $10 \cdot 0$ & $3 \cdot 4$ & \\
\hline Age group & & & $<0.001$ \\
\hline$<6$ years & $8 \cdot 5$ & $2 \cdot 8$ & \\
\hline $6-10$ years & $9 \cdot 8$ & $3 \cdot 4$ & \\
\hline$>10$ years & $10 \cdot 6$ & $2 \cdot 9$ & \\
\hline BMI classification & & & 0.003 \\
\hline Underweight and normal weight & $10 \cdot 5$ & $3 \cdot 3$ & \\
\hline Overweight & $9 \cdot 4$ & $2 \cdot 9$ & \\
\hline Obese & $9 \cdot 5$ & $3 \cdot 2$ & \\
\hline Parents' education & & & $<0.001$ \\
\hline None or primary & $8 \cdot 5$ & 4.9 & \\
\hline Secondary & $8 \cdot 3$ & $2 \cdot 6$ & \\
\hline High school & $9 \cdot 8$ & $3 \cdot 0$ & \\
\hline University & $12 \cdot 3$ & $2 \cdot 6$ & \\
\hline Parents' occupation & & & $<0.001$ \\
\hline Unskilled professions & $7 \cdot 7$ & $2 \cdot 1$ & \\
\hline Partially skilled professions & 8.9 & $2 \cdot 7$ & \\
\hline Skilled professions & $9 \cdot 7$ & $3 \cdot 2$ & \\
\hline Specialized/managerial & $11 \cdot 0$ & $3 \cdot 1$ & \\
\hline
\end{tabular}


(a)

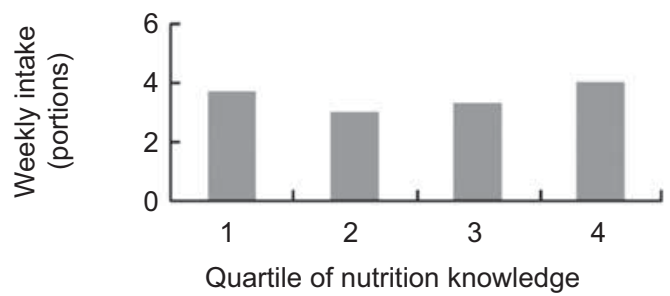

(c)

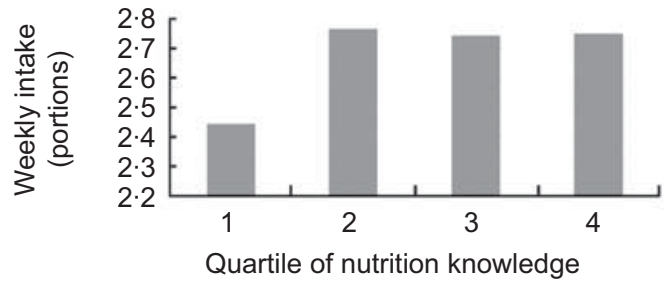

(e)

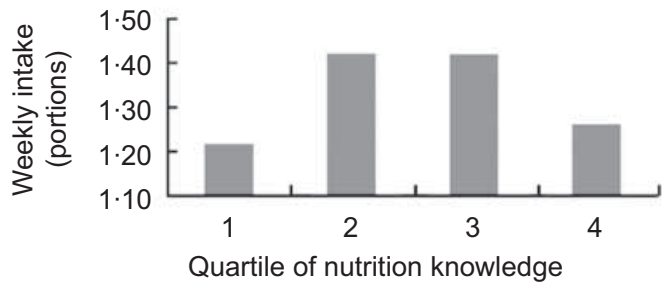

(g)

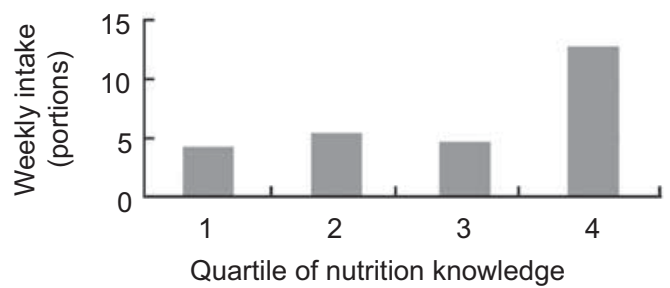

(i)

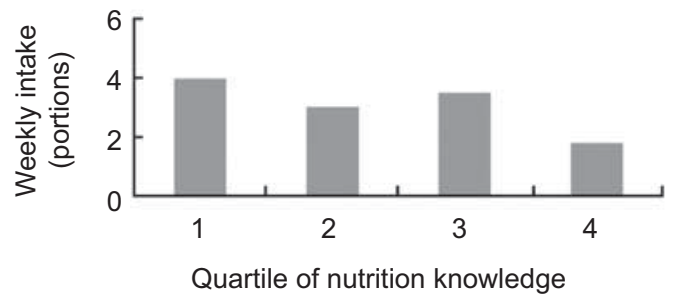

(k)

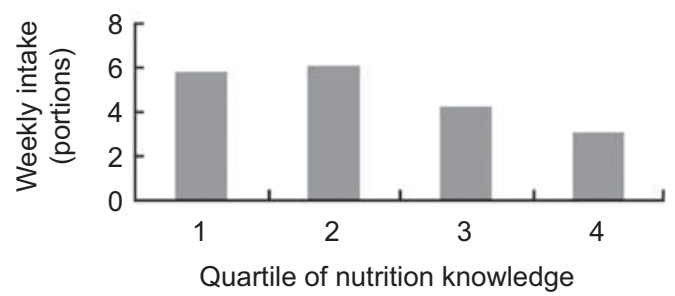

(b)

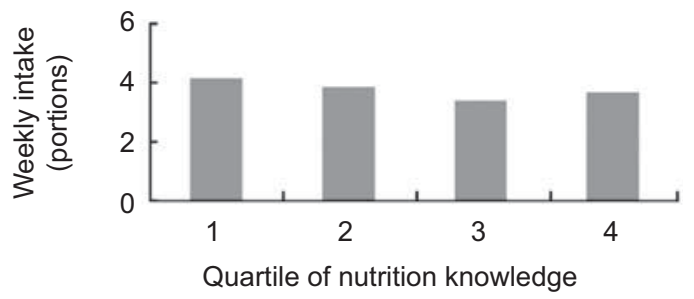

(d)

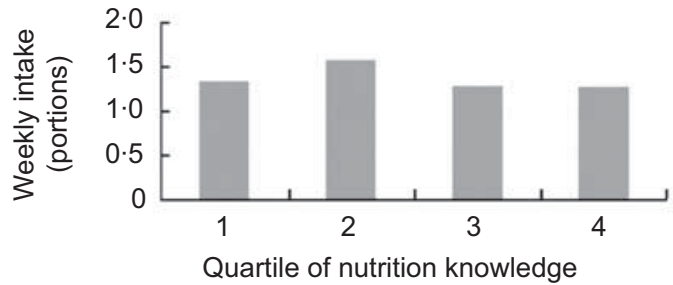

(f)

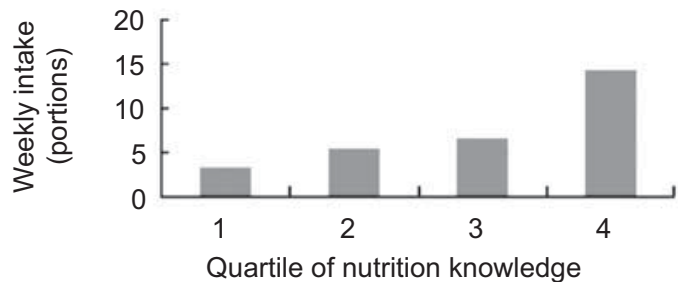

(h)

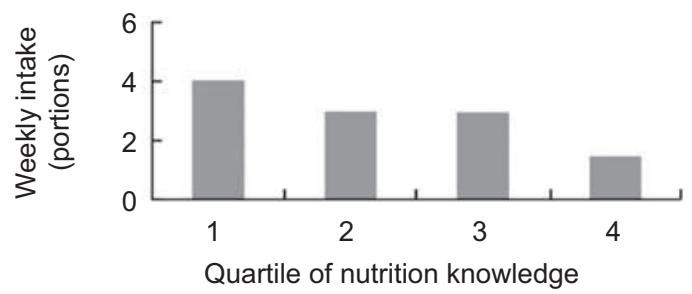

(j)

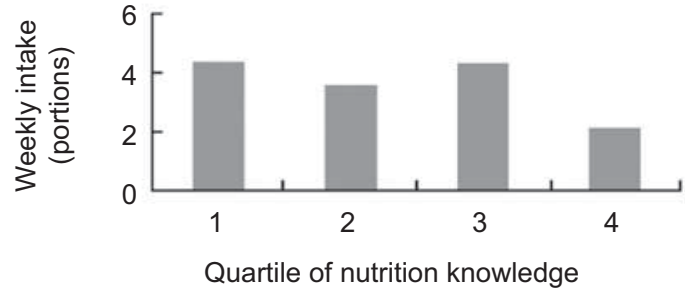

(I)

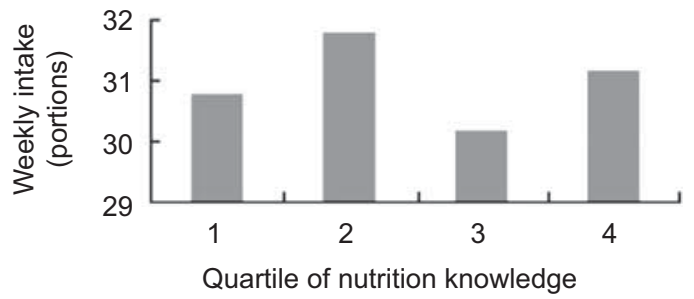

Fig. 1 Weekly food consumption according to quartile of nutrition knowledge score in children and young adolescents $(n 445)$ aged 4-16 years living in a rural area of Sicily, South Italy, 2010. (a) Pasta/rice $(P=0.001, P$ for trend $=0 \cdot 111)$; (b) meat $(P=0.015$, $P$ for trend $=0.011)$; (c) fish $(P=0.21, P$ for trend=0.119); (d) cheese $(P=0.84, P$ for trend $=0.26)$; $(e)$ eggs $(P=0.226$, $P$ for trend $=0.697)$; (f) vegetables $(P<0.001, P$ for trend $<0.001)$; $(\mathrm{g})$ fruit $(P<0.001, P$ for trend $=0.001)$; $(\mathrm{h})$ sweets $(P<0.001, P$ for trend $<0.001)$; (i) snacks $(P<0.001, P$ for trend $<0.001)$; (j) fried foods $(P<0.001, P$ for trend $<0.001)$; $(\mathrm{k})$ sugary drinks $(P=0.004, P$ for trend $=0.001)$; $(I)$ water $(P=0.695, P$ for trend $=0.914)$

being female, older and having a higher BMI were associated with physical activity, while BMI was also associated inversely with having breakfast daily and directly with frequent snacking. Regarding parents' socio-cultural level, being in the highest education category was associated with less frequent snacking and more frequent weekly physical activity, while being in the highest occupational category was associated with daily breakfast. 
Table 5 Linear regression analysis results of weekly food consumption $v$. demographic characteristics and nutrition knowledge: children and young adolescents ( $n$ 445) aged 4-16 years living in a rural area of Sicily, South Italy, 2010

\begin{tabular}{|c|c|c|c|c|c|c|c|c|c|c|c|c|}
\hline \multirow[b]{3}{*}{ Food consumption } & \multicolumn{12}{|c|}{ Covariates* } \\
\hline & \multicolumn{2}{|c|}{ Gender (female) } & \multicolumn{2}{|c|}{ Age } & \multicolumn{2}{|c|}{ BMI } & \multicolumn{2}{|c|}{ Parents' education } & \multicolumn{2}{|c|}{ Parents' occupation } & \multicolumn{2}{|c|}{ Nutrition knowledge } \\
\hline & $\beta$ & $P$ & $\beta$ & $P$ & $\beta$ & $P$ & $\beta$ & $P$ & $\beta$ & $P$ & $\beta$ & $P$ \\
\hline Pasta/rice & -0.026 & $0 \cdot 819$ & 0.042 & $0 \cdot 101$ & -0.036 & 0.253 & -0.347 & $<0.001$ & -0.019 & $0 \cdot 819$ & 0.047 & 0.022 \\
\hline Meat & $0 \cdot 124$ & $0 \cdot 125$ & -0.006 & 0.735 & 0.002 & 0.926 & -0.188 & 0.007 & -0.055 & $0 \cdot 360$ & -0.002 & 0.879 \\
\hline Fish & -0.114 & 0.242 & 0.008 & 0.706 & -0.002 & 0.946 & $-0 \cdot 108$ & 0.200 & 0.165 & 0.023 & 0.630 & $<0.001$ \\
\hline Cheese & 0.079 & 0.426 & 0.019 & 0.413 & 0.026 & 0.352 & 0.018 & 0.834 & 0.073 & 0.327 & -0.023 & 0.203 \\
\hline Eggs & 0.037 & 0.693 & -0.026 & 0.219 & 0.050 & 0.056 & -0.049 & 0.543 & $-0 \cdot 101$ & 0.146 & 0.020 & 0.232 \\
\hline Vegetables & $0 \cdot 189$ & $0 \cdot 117$ & 0.097 & $<0.001$ & -0.066 & 0.049 & 0.226 & 0.029 & 0.328 & $<0.001$ & 0.203 & $<0.001$ \\
\hline Fruit & 0.300 & 0.030 & 0.066 & 0.036 & -0.083 & 0.031 & 0.253 & 0.033 & 0.228 & 0.027 & $0 \cdot 129$ & $<0.001$ \\
\hline Sweets & -0.061 & 0.573 & 0.004 & 0.855 & 0.068 & 0.024 & -0.074 & 0.826 & 0.096 & 0.234 & -0.168 & $<0.001$ \\
\hline Snacks & $-0 \cdot 165$ & 0.207 & -0.019 & 0.523 & 0.091 & 0.013 & -0.304 & 0.007 & 0.030 & 0.758 & -0.090 & $<0.001$ \\
\hline Fried foods & -0.205 & $0 \cdot 169$ & -0.008 & $0 \cdot 808$ & 0.088 & 0.035 & -0.422 & 0.001 & 0.041 & $0 \cdot 715$ & -0.066 & 0.016 \\
\hline Sugary drinks & $-0 \cdot 103$ & 0.556 & -0.038 & 0.341 & $0 \cdot 158$ & 0.001 & -0.438 & 0.004 & 0.071 & 0.583 & -0.080 & 0.012 \\
\hline
\end{tabular}

Statistically significant coefficients are indicated in bold font.

${ }^{*}$ All variables included in the model simultaneously.

Given the differences found in student age, we divided the cohort into two subgroups: (i) children (age 4-12 years) and (ii) young adolescents (age 13-16 years). Applying such a division in all the aforementioned analyses revealed mostly identical results to those obtained by considering the cohort as a whole. Where statistically significant differences regarding the associations between nutrition knowledge and several variables were observed, these in most cases were following the pattern of a gradually increasing or decreasing association in both children and adolescents. On the other hand, we failed in demonstrate a significant association between nutrition knowledge and BMI in adolescents (data not shown).

\section{Discussion}

In the present study the associations between nutrition knowledge, food intake and some dietary and lifestyle behaviours among children and young adolescents living in a rural area of Sicily were explored, and a positive association was found between nutrition knowledge and healthier nutritional behaviour. Demographic and social factors were also found to be independent determinants of such outcomes. Although multiple factors influence food consumption and nutritional habits in childhood and adolescence, most previous studies assessed only specific aspects (i.e. fruit and vegetable intake or breakfast habits) and only a few have investigated the associations between nutrition knowledge, consumption of several food groups and lifestyle factors simultaneously. According to our knowledge, the present study is the first one investigating such correlates in a representative sample of children and young adolescents living in a rural area of Sicily, South Italy. Also, our study was strengthened by a psychometrically reliable questionnaire on nutritional habits, lifestyle and nutrition knowledge specifically developed for children and young adolescents.
In our study, about half of the students demonstrated acceptable knowledge about energy expenditure activities and food content; they were aware of the importance of some healthy foods but knowledge about nutrient functions and macronutrients was weak. We also found that knowledge level played a relevant role in pasta/rice, fish, fruit, vegetables, sweets, snacks, fried foods and sugary drinks consumption as well as in sedentary activities and frequent snacking. Other investigators, in comparable studies, have found a positive impact of knowledge on food consumption and nutritional behaviour in children and adolescents. A survey performed in Iceland demonstrated that knowledge of fruit and vegetable recommendations had a positive impact on their consumption ${ }^{(3)}$. In an Austrian study, nutrient intake showed close coherence to the degree of nutrition knowledge ${ }^{(4)}$. In US students, eating behaviours correlated with nutrition knowledge especially in older students ${ }^{(5,10)}$. A possible relevant role of knowledge in affecting nutritional behaviour and food choices may depend on student awareness of recommendations and food constituents that might positively be related to food intake. Moreover, increasing lifestyle education, including skills necessary for understanding the importance of physical activity, might increase the frequency of such healthy behaviour. These assumptions are confirmed by several studies that provided intervention programmes aimed at increasing nutrition knowledge in children and adolescents and resulted in an association between increased knowledge and more healthy food consumption or lifestyle habits ${ }^{(11-13)}$.

To describe dietary intake and food habits in young people, it is relevant to associate such eating behaviour with knowledge and to understand them with regard to personal and environmental factors in the context of a modern society ${ }^{(14)}$. Scientific studies have been conducted mostly on adolescents, rather than on children, even with contrasting results ${ }^{(15)}$. Our study found that older age was independently associated with a higher 
consumption of fruit and vegetables as well as having more frequent weekly physical activity. Differences between these age stages could be expected because adolescents experience several changes in social influences $^{(16)}$. Moreover, being older could be associated with a higher nutrition knowledge level and, consequently, healthier dietary and lifestyle habits.

Among the other demographic characteristics, our study revealed that BMI was associated with unhealthy food consumption (positively with sweets, snacks, fried foods and sugary drinks; negatively with fruit and vegetables) and lifestyle habits (such as skipping breakfast, frequent snacking and infrequent physical activity). Several studies reported similar findings. The proportion of overweight or obese students has usually been found to be lower in those taking breakfast daily ${ }^{(17,18)}$ and higher among those having unhealthy dietary ${ }^{(19)}$ and beverage patterns ${ }^{(20)}$ and with a sedentary-snacking pattern ${ }^{(21)}$.

Children have particular food choices and meal habits, such as irregular eating pattern, frequent snacking and skipping breakfast, that are typically set up in this period of life and will affect nutritional habits in subsequent adolescence. In contrast to such dynamic behavioural choices in children that would be expected to vary depending on their own will, intake of specific foods may depend on their availability in the home, which is a factor strictly associated with family lifestyle characteristics and nutritional habits. In our study, parents' educational level and occupational category, considered as a surrogate of socio-cultural level, were shown to have an influence on the consumption of specific foods. This might suggest that students from families with a lower socio-cultural level face certain barriers to complying with a healthful diet, possibly due to fewer financial resources for the purchase of healthier foods or lack of knowledge regarding nutritional recommendations for healthy eating. Socio-economic status has been examined in a large number of studies in association with children's and adolescents' food intake, indicating that parental occupation and parental education are positively associated with specific food consumption and suggesting that family circumstance factors may be a significantly important influence on dietary intake and on dietary behaviours for children and adolescents ${ }^{(15,22,23)}$. Food consumption may reflect poor home food availability ${ }^{(24,25)}$ and family environment ${ }^{(22,23)}$, as well as poor parental role modelling ${ }^{(26)}$ and parenting style ${ }^{(27)}$. Some recent studies conducted in the European setting have assessed the relationship between fruit and vegetable consumption and food-related family lifestyle ${ }^{(28-30)}$. Finally, a higher nutrition knowledge among parents has been shown to correlate with higher fruit and vegetable consumption in children ${ }^{(23,31)}$. This supports the assumption that nutrition knowledge mediates some of the socio-economic status variation in food intake, especially for fruit and vegetables $^{(32,33)}$. 
Findings in the current paper should be treated in the light of several limitations. First, the study design was cross-sectional. Thus, conclusions cannot be attributed to plausible causes, but rather valuable assumptions that could be used for further investigation. As with any self-reported survey, misreporting bias should be taken into account. More valid data would probably result from a design that uses multiple sources (i.e. students, teachers and parents). Moreover, only crude measures were used to collect dietary data, using a single question for each item with no reference to the portion size or amount consumed. However, given that the topics investigated in the questionnaire are quite complex and the target population for which it was designed is difficult to manage in terms of comprehension of the significance of the items because of young age, any attempt to create a 'perfect' instrument is impossible. Second, as the information on both nutrition knowledge and food consumption comes from self-reports, it is possible that there is a tendency of respondents to answer questions in a manner that will be viewed favourably by others (social acceptability bias). This can bias the interpretation of the tendencies as well as individual differences. Third, although the sample was representative of a typical rural area in Sicily, our sample is composed of children in a single area. Therefore, it does not permit generalization of the results, even though there is no reason to hypothesize differences among areas of a culturally homogeneous island such as Sicily.

\section{Conclusions}

The present findings add to other results in the literature in suggesting that nutrition knowledge is an important target for health education and has the potential to improve especially the dietary habits and lifestyle behaviours of children and young adolescents. Age has a central role in this issue, and improving nutrition knowledge in young people may translate into educating them in good dietary habits. In order to promote healthy nutritional behaviours and prevent overweight and obesity, it is important to target this population with interventions concerning their eating habits and lifestyles. Moreover, given the strong role of parental socio-economic and educational status on children's behaviour, nutrition intervention programmes should involve them as well, to improve dietary quality and nutritional habits of the entire family.

\section{Acknowledgements}

G.G. was supported by the International PhD Program in Neuropharmacology, University of Catania Medical School, Catania, Italy. All authors declare that they do not have a commercial relationship (i.e. consultancies, patent-licensing agreements) that might pose a conflict of interest in connection with the present paper. G.G. and A.M. designed the study, provided data and wrote the manuscript; G.T. and H.C. analysed data and provided results; C.R. and F.G. provided a critical review of the manuscript. The authors are grateful to Susanne Lukowicz for English language editing.

\section{Supplementary Materials}

For Supplementary Materials for this article, please visit http://dx.doi.org/10.1017/S1368980012003965.

\section{References}

1. Harnack L, Block G, Subar A et al. (1997) Association of cancer prevention-related nutrition knowledge, beliefs, and attitudes to cancer prevention dietary behavior. $J \mathrm{Am}$ Diet Assoc 97, 957-965.

2. Guo SS, Wu W, Chumlea WC et al. (2002) Predicting overweight and obesity in adulthood from body mass index values in childhood and adolescence. Am J Clin Nutr 76, 653-658.

3. Kristjansdottir AG, Thorsdottir I, De Bourdeaudhuij I et al. (2006) Determinants of fruit and vegetable intake among 11-year-old schoolchildren in a country of traditionally low fruit and vegetable consumption. Int J Behav Nutr Phys Act 3, 41 .

4. Godina-Zarfel B \& Elmadfa I (1993) Food preferences, nutritional knowledge and their impact on nutrient intake in Austrian children and adolescents. Nutrition 17, 314-315.

5. Pirouznia M (2001) The association between nutrition knowledge and eating behavior in male and female adolescents in the US. Int J Food Sci Nutr 52, 127-132.

6. Lawshe $\mathrm{CH}$ (1975) A quantitative approach to content validity. Pers Psychol 28, 563-575.

7. Cole TJ, Bellizzi MC, Flegal KM et al. (2000) Establishing a standard definition for child overweight and obesity worldwide: international survey. BMJ 320, 1240-1243.

8. Cronbach LJ (1951) Coefficient alpha and the internal structure of tests. Psychometrika 16, 297-334.

9. De Vellis RF (1991) Scale Development Theory and Applications. London: SAGE Publications.

10. Pirouznia M (2000) The correlation between nutrition knowledge and eating behavior in an American school: the role of ethnicity. Nutr Health 14, 89-107.

11. Gower JR, Moyer-Mileur LJ, Wilkinson RD et al. (2010) Validity and reliability of a nutrition knowledge survey for assessment in elementary school children. J Am Diet Assoc 110, 452-456.

12. Warren JM, Henry CJ, Lightowler HJ et al. (2003) Evaluation of a pilot school programme aimed at the prevention of obesity in children. Health Promot Int 18, 287-296.

13. Nix ST, D’Agostino IC, Strobino BA et al. (1999) Developing a computer-assisted health knowledge quiz for preschool children. J Sch Health 69, 9-11.

14. Story M, Neumark-Sztainer D \& French S (2002) Individual and environmental influences on adolescent eating behaviors. J Am Diet Assoc 102, 3 Suppl., S40-S51.

15. Rasmussen M, Krolner R, Klepp KI et al. (2006) Determinants of fruit and vegetable consumption among children and adolescents: a review of the literature. Part I: Quantitative studies. Int J Behav Nutr Phys Act 3, 22.

16. Kusano-Tsunoh A, Nakatsuka H, Satoh H et al. (2001) Effects of family-togetherness on the food selection by primary and junior high school students: family-togetherness means better food. Tohoku J Exp Med 194, 121-127. 
17. Ayranci U, Erenoglu N \& Son O (2010) Eating habits, lifestyle factors, and body weight status among Turkish private educational institution students. Nutrition 26, 772-778.

18. Dubois L, Girard M, Potvin KM et al. (2009) Breakfast skipping is associated with differences in meal patterns, macronutrient intakes and overweight among pre-school children. Public Health Nutr 12, 19-28.

19. Jodkowska M, Oblacinska A, Tabak I et al. (2011) Differences in dietary patterns between overweight and normal-weight adolescents. Med Wieku Rozwoj 15, 266-273.

20. LaRowe TL, Moeller SM \& Adams AK (2007) Beverage patterns, diet quality, and body mass index of US preschool and school-aged children. J Am Diet Assoc 107, 1124-1233.

21. Gubbels JS, Kremers SP, Goldbohm RA et al. (2012) Energy balance-related behavioural patterns in 5-year-old children and the longitudinal association with weight status development in early childhood. Public Health Nutr 15, $1402-1410$.

22. van der Horst K, Oenema A, Ferreira I et al. (2007) A systematic review of environmental correlates of obesityrelated dietary behaviors in youth. Health Educ Res 22, 203-226.

23. Pearson N, Biddle SJ \& Gorely T (2009) Family correlates of fruit and vegetable consumption in children and adolescents: a systematic review. Public Health Nutr 12, 267-283.

24. Neumark-Sztainer D, Wall M, Perry C et al. (2003) Correlates of fruit and vegetable intake among adolescents. Findings from Project EAT. Prev Med 37, 198-208.

25. Tak NI, te Velde SJ \& Brug J (2008) Are positive changes in potential determinants associated with increased fruit and vegetable intakes among primary school-children?
Results of two intervention studies in the Netherlands: the School-gruiten Project and the Pro Children Study. Int $J$ Behav Nutr Phys Act 5, 21-32.

26. De Bourdeaudhuij I \& Van Oost P (2000) Personal and family determinants of dietary behaviour in adolescents and their parents. Psychol Health 15, 751-770.

27. Kremers SP, Brug J, de Vries H et al. (2003) Parenting style and adolescent fruit consumption. Appetite 41, 43-50.

28. Verzeletti C, Maes L, Santinello M et al. (2010) Foodrelated family lifestyle associated with fruit and vegetable consumption among young adolescents in Belgium Flanders and the Veneto Region of Italy. Appetite 54, 394-397.

29. Wind M, de Bourdeaudhuij I, te Velde SJ et al. (2006) Correlates of fruit and vegetable consumption among 11-year-old Belgian-Flemish and Dutch schoolchildren. J Nutr Educ Behav 38, 211-221.

30. De Bourdeaudhuij I, te Velde S, Brug J et al. (2008) Personal, social and environmental predictors of daily fruit and vegetable intake in 11-year-old children in nine European countries. Eur J Clin Nutr 62, 834-841.

31. te Velde SJ, Wind M, van Lenthe FJ et al. (2006) Differences in fruit and vegetable intake and determinants of intakes between children of Dutch origin and non-Western ethnic minority children in the Netherlands - a cross sectional study. Int J Behav Nutr Phys Act 3, 31.

32. Wardle J, Parmenter K \& Waller J (2000) Nutrition knowledge and food intake. Appetite 34, 269-275.

33. Parmenter K, Waller J \& Wardle J (2000) Demographic variation in nutrition knowledge in England. Health Educ Res 15, 163-174. 